\title{
Structrual Difference in Macro-RAFT agents redirects Polymerization-Induced Self-Assembly
}

\author{
Yuxuan Zhang ${ }^{\mathrm{a}}$, Liangliang Yu ${ }^{\mathrm{a}}$, Xiaocong Dai ${ }^{\mathrm{a}}$, Li Zhang ${ }^{\mathrm{a}, \mathrm{b}}$, Jianbo Tan ${ }^{\text {a,b }}$
}

a. Department of Polymeric Materials and Engineering, School of Materials and Energy, Guangdong University of Technology, Guangzhou 510006, China.

b. Guangdong Provincial Key Laboratory of Functional Soft Condensed Matter, Guangzhou 510006, China.

*Corresponding author: tanjianbo@gdut.edu.cn

Yuxuan Zhang and Liangliang Yu contributed equally to this work. 


\section{EXPERIMENTAL SECTION}

\section{Material}

2-Hydroxypropyl methacrylate (HPMA, Aladdin), poly(ethylene glycol) methyl ether methacrylate (PEGMA, $M_{\mathrm{n}}=500 \mathrm{~g} / \mathrm{mol}$, Sigma-Aldrich), glycidyl methacrylate (GlyMA, Aladdin), poly(ethylene glycol) methyl ether acrylate (PEGA, $M_{\mathrm{n}}=480 \mathrm{~g} / \mathrm{mol}$, Sigma-Aldrich), ethylene diamine anhydrous (EDA, Tianjin Damao Chemical Factory ), hydroquinone (Aladdin), and hydroxyethyl acrylate(HEA, Aladdin) were used as received. Azobisisobutyronitrile (AIBN, Aladdin) was recrystallized from ethanol prior to storage under refrigeration at $4{ }^{\circ} \mathrm{C}$. 4-Cyano-4-(dodecylsulfanylthiocarbonyl)sulfanylpentanoic acid (CDPA) was synthesized according to a literature ${ }^{1}$. Sodium phenyl-2,4,6-trimethylbenzoylphosphinate (SPTP) was synthesized according to a literature ${ }^{2}$. LED lamps (405 nm) were purchased from Huaenopto (Zhejiang).

\section{Characterization}

Transmission electron microscopy (TEM). The obtained dispersions were diluted 100-fold with water. A drop of the solution was placed on a copper grid for 1 min and then blotted with filter paper to remove excess solution. A drop of uranyl acetate solution $(0.5 \mathrm{wt} \%)$ was soaked on the same copper grid for $1.5 \mathrm{~min}$, and then blotted with filter paper to remove excess strain. TEM observations were carried out on a Hitachi 7700 instrument operated at $120 \mathrm{kV}$.

Gel permeation chromatography (GPC). The molecular weight and polydispersity of the block copolymers were measured by gel permeation chromatography (GPC) at $50{ }^{\circ} \mathrm{C}$ using a Waters 1515 GPC instrument with dimethylformamide (DMF) (containing $10 \mathrm{mM} \mathrm{LiBr}$ ) as the mobile phase and Waters styragel HR1 and HR4 columns. The flow rate of DMF was $1.0 \mathrm{~mL} / \mathrm{min}$. Linear 
polymethacrylate polymers with narrow molecular weight distributions were used as the standards to calibrate apparatus.

${ }^{1} H$ NMR spectroscopy. Nuclear magnetic resonance (NMR) spectra were recorded in $\mathrm{CDCl}_{3}$ or DMSO- $d_{6}$ using a Bruker Avance III HD $400 \mathrm{MHz}$ NMR spectrometer at a temperature of $25^{\circ} \mathrm{C}$.

Dynamic light scattering (DLS). Intensity-average hydrodynamic diameters of the copolymer dispersions were determined using a Malvern Zetasizer Nano ZS instrument. Dilute aqueous dispersions were analyzed using disposable cuvettes and all data were averaged over three consecutive runs.

Atomic force microscopy (AFM). Atomic force microscopy was measured using a Bruker Dimension FastScan AFM system with Fastscan-C Probes. Samples were usually scanned twice in tapping mode at 2 sampling points (scan area $2 \times 2 \mu \mathrm{m}$, and $8 \times 8 \mu \mathrm{m}, 256$ lines, scan speed $=2.94 \mathrm{~Hz}$, optimized for high resolution of the specific surface). The raw AFM data were processed using Plane Fitting within the Bruker Nanoscope Analysis software.

Fourier transform infrared (FTIR). Each lyophilized sample in advance was ground up with $\mathrm{KBr}$ to form a fine power and compressed into a pallet. The FTIR spectra were recorded using a Nicolet 6700 spectrometer.

Optical microscopy $(O M)$. The emulsion images were recorded using an optical microscope (BK-POL, Chongqing, China) with a built-in-camera.

\section{Synthesis of PPEGMA15.6-CDPA}

The synthesis of PPEGMA ${ }_{15.6}$-CDPA is given below: PEGMA (20.00 g, $\left.40 \mathrm{mmol}\right)$, CDPA (0.95 g, $2.35 \mathrm{mmol})$, AIBN (0.077 g, $0.47 \mathrm{mmol})$, and 1,3,5-trioxacyclohexane (0.37 g, $4.11 \mathrm{mmol})$, and 1,4-dioxane $(20.0 \mathrm{~g})$ were weighed into a $100 \mathrm{~mL}$ round bottom flask and purged with nitrogen for 45 min. The flask was then immersed into a preheated oil bath at $70{ }^{\circ} \mathrm{C}$ for $4.6 \mathrm{~h}$ (Monomer 
conversion $=92 \%$ as judged by ${ }^{1} \mathrm{H}$ NMR). The polymerization was then quenched by immersion in ice water and exposure to air. The product was precipitated by excess hexane $(300 \mathrm{~mL})$ and washed several times with additional hexane. The precipitated product was then dried at $45{ }^{\circ} \mathrm{C}$ under vacuum overnight. Other PPEGMA ${ }_{n}$-CDPA macro-RAFT agents were synthesized following the same protocol.

\section{Synthesis of PPEGA15.6-CDPA}

The synthesis of PPEGA ${ }_{15.6}$-CDPA is given below: PEGA (20.00 g, $\left.41.6 \mathrm{mmol}\right)$, CDPA (0.93 g, $2.31 \mathrm{mmol})$, AIBN (0.076 g, $0.46 \mathrm{mmol})$, and 1,3,5-trioxacyclohexane (0.37 g, $4.09 \mathrm{mmol})$, and 1,4-dioxane $(20.00 \mathrm{~g})$ were weighed into a $100 \mathrm{~mL}$ round bottom flask and purged with nitrogen for $45 \mathrm{~min}$. The flask was then immersed into a preheated oil bath at $70{ }^{\circ} \mathrm{C}$ for $3 \mathrm{~h}$ (Monomer conversion $=86.7 \%$ as judged by ${ }^{1} \mathrm{H}$ NMR). The polymerization was then quenched by immersion in ice water and exposure to air. The product was precipitated by excess $n$-hexane $(300 \mathrm{~mL})$ and washed several times with additional $n$-hexane. The precipitated product was then dried at $45{ }^{\circ} \mathrm{C}$ under vacuum overnight. Other PPEGA $\mathrm{n}_{\mathrm{n}}$-CDPA macro-RAFT agents were synthesized following the same protocol.

\section{Synthesis of PHEA59.5-CDPA}

The synthesis of PHEA59.5-CDPA is given below: HEA (15.00 g, $129.2 \mathrm{mmol})$, CDPA (0.78 g, $1.93 \mathrm{mmol}), \operatorname{AIBN}(0.032 \mathrm{~g}, 0.20 \mathrm{mmol})$, 1,3,5-trioxacyclohexane (1.16 g, $12.87 \mathrm{mmol})$, and 1,4-dioxane $(60.00 \mathrm{~g})$ were weighed into a $250 \mathrm{~mL}$ round bottom flask and purged with nitrogen for 45 min. The flask was then immersed into a preheated oil bath at $65{ }^{\circ} \mathrm{C}$ for $4.3 \mathrm{~h}$ (Monomer conversion $=88.83 \%$ as judged by ${ }^{1} \mathrm{H}$ NMR). The polymerization was then quenched by immersion in ice water and exposure to air. The product was precipitated by excess $n$-hexane $(300 \mathrm{~mL})$ and washed several times with additional $n$-hexane. The precipitated product was then dried at $45{ }^{\circ} \mathrm{C}$ 
under vacuum overnight. The polymer was analyzed by DMF GPC with $M_{\mathrm{n}}=16.0 \mathrm{~kg} / \mathrm{mol}$ and $M_{\mathrm{w}} / M_{\mathrm{n}}=1.11$ as determined by reference to polymethylmethacrylate standards.

\section{Photoinitiated RAFT-mediated PISA of PPEGA15.6-PHPMA400 (10\% w/w HPMA)}

In a typical experiment, HPMA (1.00 g, 6.94 mmol), PPEGA $15.6-\mathrm{CDPA}(0.14 \mathrm{~g}, 0.017 \mathrm{mmol})$, SPTP (1.8 mg, $0.0058 \mathrm{mmol})$, and 1, 3, 5-trioxacyclohexane (0.064 g, $0.71 \mathrm{mmol})$ were weighed into a $25 \mathrm{~mL}$ round bottom flask. Then a certain amount of water $(9.00 \mathrm{~g}$ in this case) was added to the flask to dissolve all reagents. The reaction mixture was purged with nitrogen for $20 \mathrm{~min}$, sealed, and then irradiated by a visible light LED lamp (405 nm, light intensity $0.45 \mathrm{~mW} / \mathrm{cm}^{2}$ ) at room temperature for $60 \mathrm{~min}$. The reaction was quenched by exposure to air. Other diblock copolymers prepared using PPEGMA $A_{n}-\mathrm{CDPA}$ or $\mathrm{PPEGA}_{\mathrm{n}} \mathrm{CDPA}$ as the macro-RAFT agent were prepared following the same protocol.

Kinetic study of photoinitiated RAFT-mediated PISA of PPEGA15.6-PHPMA200 (20\% w/w HPMA)

HPMA (2.00 g, $13.87 \mathrm{mmol})$, PPEGA 15.6 -CDPA (0.55 g, $0.069 \mathrm{mmol})$, SPTP (7.2 mg, 0.023 $\mathrm{mmol})$, DSS $(0.04 \mathrm{~g})$ and water $(8.00 \mathrm{~g}$ in this case) were weighed into a $25 \mathrm{~mL}$ round bottom flask. The reaction mixture was then purged with nitrogen for $20 \mathrm{~min}$, sealed, and then irradiated by a visible light LED lamp (405 $\mathrm{nm}$, light intensity $\left.0.45 \mathrm{~mW} / \mathrm{cm}^{2}\right)$ at $25^{\circ} \mathrm{C}$. Samples were withdrawn at predetermined time intervals by syringes under nitrogen. The polymerizations were quenched by exposure to air and the addition of a small amount of hydroquinone. The samples (typically $0.5 \mathrm{~g}$ ) were then analysis by ${ }^{1} \mathrm{H}$ NMR spectroscopy and DMF GPC. 
Kinetic study of photoinitiated RAFT-mediated PISA of PPEGMA15.6-PHPMA200 (20\% w/w HPMA)

HPMA (2.00 g, 13.87 mmol), PPEGMA 15.6 -CDPA (0.57 g, 0.069 mmol), SPTP (7.2 mg, 0.023 $\mathrm{mmol})$, DSS (0.04 g), and water (8.00 $\mathrm{g}$ in this case) were weighed into a $25 \mathrm{~mL}$ round bottom flask. The reaction mixture was purged with nitrogen for $20 \mathrm{~min}$, sealed, and then irradiated by a visible light LED lamp (405 $\mathrm{nm}$, light intensity $0.45 \mathrm{~mW} / \mathrm{cm}^{2}$ ) at $25{ }^{\circ} \mathrm{C}$. Samples were withdrawn at predetermined time intervals by syringes under nitrogen. The polymerizations were quenched by exposure to air and the addition of a small amount of hydroquinone. The samples (typically $0.5 \mathrm{~g}$ ) were then analysis by ${ }^{1} \mathrm{H}$ NMR spectroscopy and DMF GPC.

Preparation of PPEGA15.6-PHPMAn $(n=800,1200,1600,2000)$ particles via two-step photoinitiated RAFT-mediated PISA

PPEGA $_{15.6}$-PHPMA 400 dispersion (10\% w/w HPMA concentration) was prepared according to the protocol as mentioned above. A degassed solution containing HPMA (0.49 g, 3.40 mmol), SPTP $(1.2 \mathrm{mg}, 0.0039 \mathrm{mmol})$ and water $\left(5.01 \mathrm{~g}\right.$ in this case) was added to the PPEGA $15.6-\mathrm{PHPMA}_{400}$ dispersion $(5.00 \mathrm{~g})$. The reaction mixture was then irradiated by a visible light LED lamp (405 nm, light intensity $0.5 \mathrm{~mW} / \mathrm{cm}^{2}$ ) at room temperature for $60 \mathrm{~min}$. The polymerization was quenched by exposure to air.

Preparation of PPEGA15.6-PHPMA400-PGlyMAn $(n=100,200,300)$ multicompartment block copolymer particles (MBCPs) via two-step photoinitiated RAFT-mediated PISA

PPEGA $_{15.6}$-PHPMA 400 dispersion (10\% w/w HPMA concentration) was prepared according to the protocol as mentioned above. In a typical experiment for the preparation of

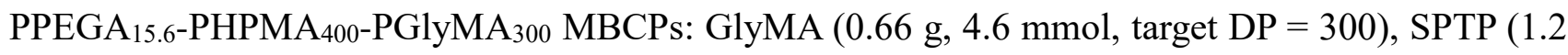


$\mathrm{mg}, 0.0039 \mathrm{mmol})$ and water $(6.98 \mathrm{~g}$ in this case) were added to the PPEGA 15.6 -PHPMA 400 dispersion $(9.01 \mathrm{~g})$. The reaction mixture was purged with nitrogen for $20 \mathrm{~min}$, sealed, and then irradiated by a visible light LED lamp (405 nm, light intensity $\left.0.5 \mathrm{~mW} / \mathrm{cm}^{2}\right)$ at room temperature for 60 min. The polymerization was quenched by exposure to air.

\section{Cross-linking of PPEGA15.6-PHPMA400-PGlyMA300 nanoparticles}

In a typical experiment, an aqueous dispersion of PPEGA $15.6-\mathrm{PHPMA}_{400}-\mathrm{PGlyMA}_{300}(1.35 \mathrm{~g}$, $7.5 \% \mathrm{w} / \mathrm{w}$, containing $2.8 \mathrm{mmol}$ epoxy group) was weighed into a vial, following the addition of ethylene diamine $(0.17 \mathrm{~g}$, containing $5.7 \mathrm{mmol}$ amine group). The reaction was continued for $24 \mathrm{~h}$ at room temperature under magnetic stirring. After the reaction, the sample was purified by several centrifugation-redispersion to remove free ethylene diamine.

\section{Pickering emulsion stabilized with PPEGA15.6-PHPMA400-PGlyMAn MBCPs}

$n$-Hexane $(2.0 \mathrm{~g})$ was homogenized with $4.0 \mathrm{~g}$ of a $0.1-5 \% \mathrm{w} / \mathrm{w}$ aqueous dispersion of PPEGA $_{15.6}$-PHPMA400-PGlyMA 300 MBCPs for 2 min using a FSH-2A homogenizer at $12000 \mathrm{rpm}$. The diameters of emulsions were measured by optical microscopy. 


\section{ADDITIONAL RESULTS}

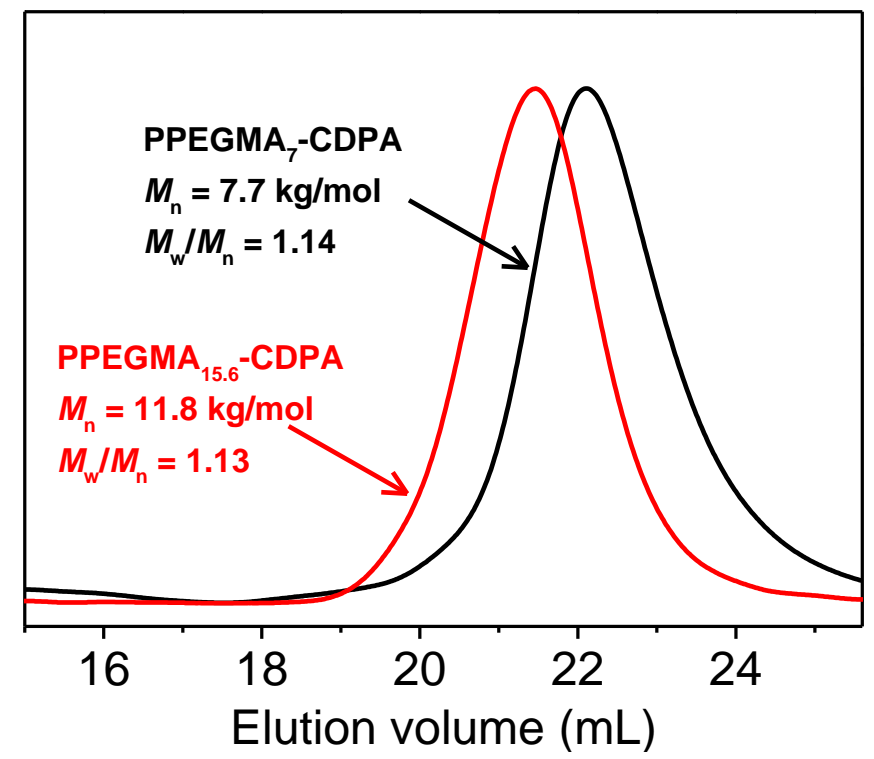

Figure S1. DMF GPC traces of PPEGMA 7 -CDPA and PPEGMA ${ }_{15.6}-\mathrm{CDPA}$.

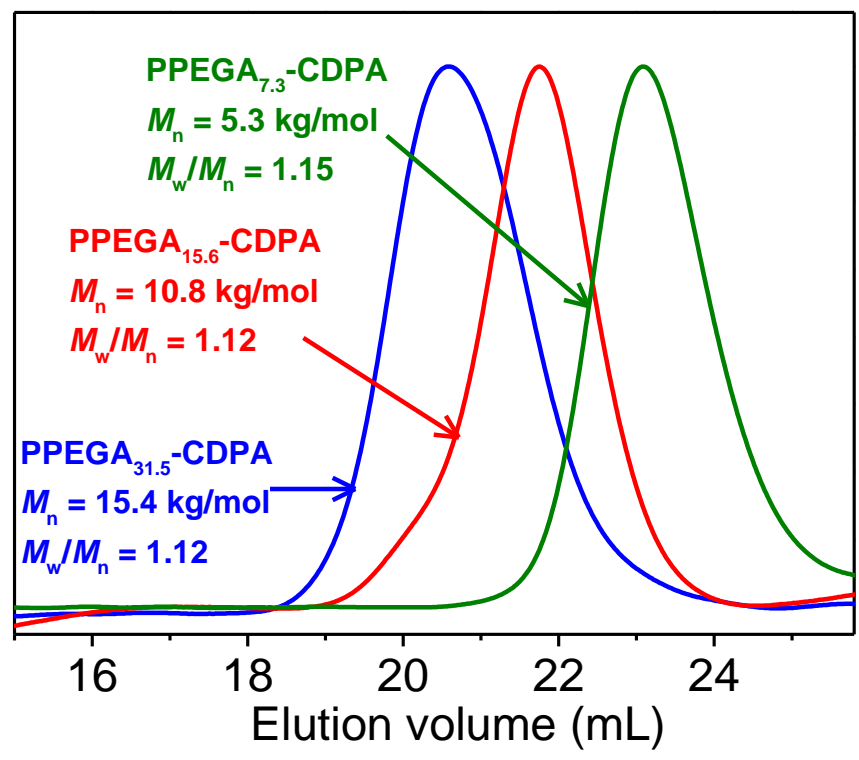

Figure S2. DMF GPC traces of PPEGA $7.3-\mathrm{CDPA}, \mathrm{PPEGA}_{15.6}-\mathrm{CDPA}$ and PPEGA ${ }_{31.5}-\mathrm{CDPA}$. 

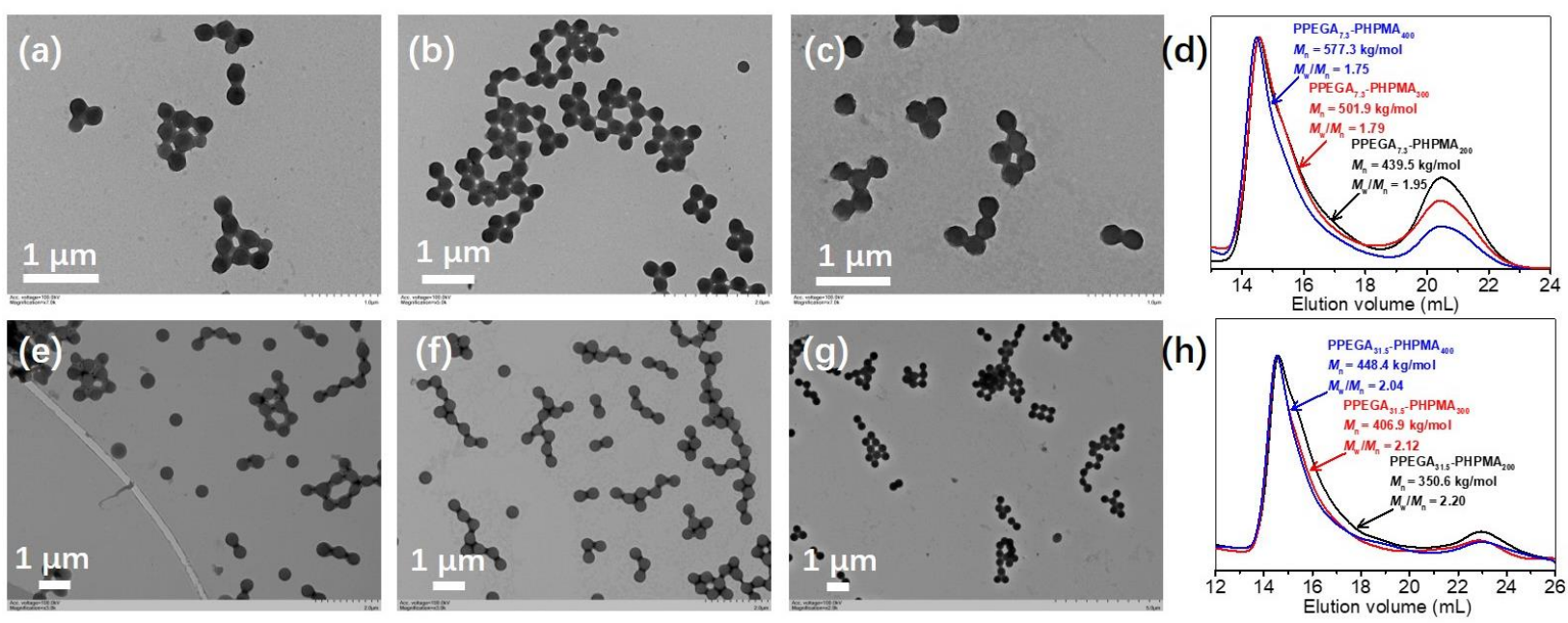

Figure S3. (a-c) TEM images and (d) GPC traces of PPEGA ${ }_{7.3}-P_{H P M A}$ prepared by photoinitiated RAFT-mediated PISA of HPMA $(10 \% \mathrm{w} / \mathrm{w})$ using PPEGA ${ }_{7.3}$-CDPA as the macro-RAFT agent: (a) $n$ $=200,(\mathrm{~b}) \mathrm{n}=300$, (c) $\mathrm{n}=400$. (e-g) TEM images and (h) GPC traces of PPEGA $31.5-\mathrm{PHPMA}_{\mathrm{n}}$ prepared by photoinitiated RAFT-mediated PISA of HPMA $(10 \% \mathrm{w} / \mathrm{w})$ using PPEGA 31.5 -CDPA as the macro-RAFT agent: (e) $n=200$, (f) $n=300$, (g) $n=400$.

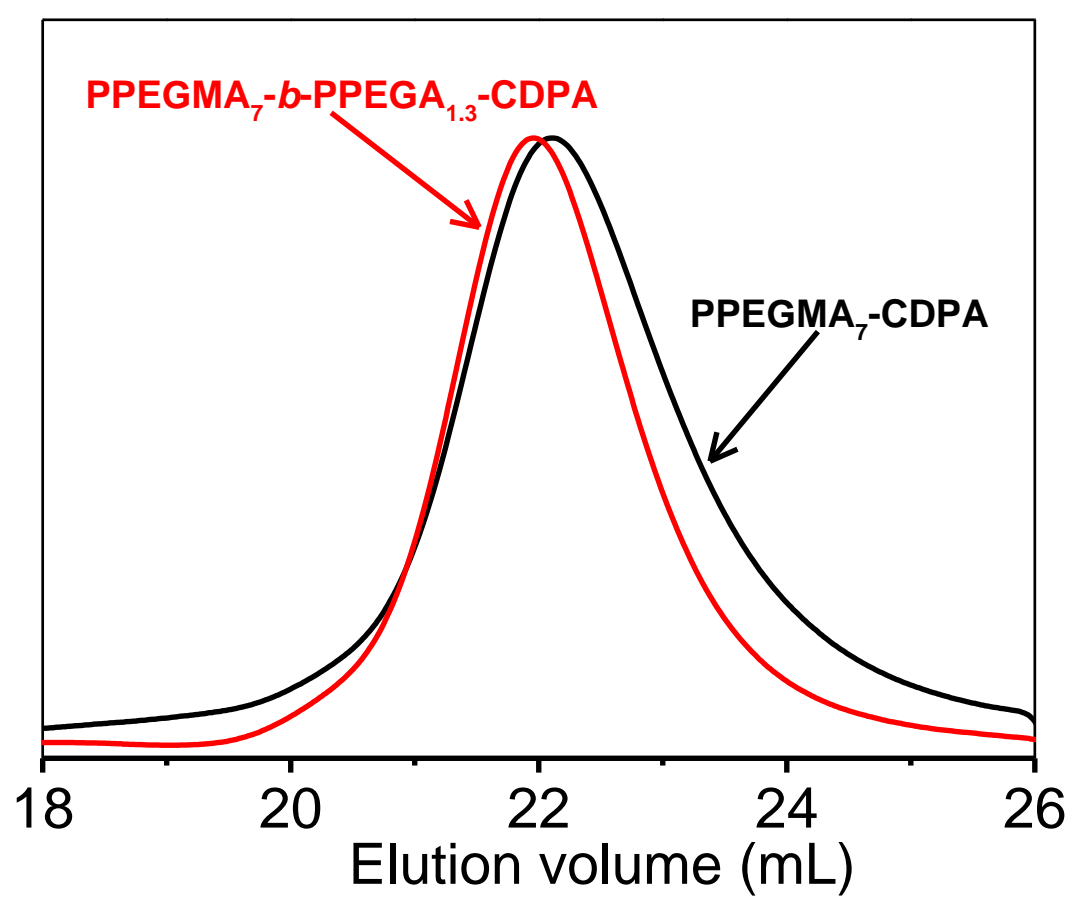

Figure S4. GPC traces of PPEGMA 7 -CDPA and PPEGMA $7-b$-PPEGA ${ }_{1.3}-\mathrm{CDPA}$. 


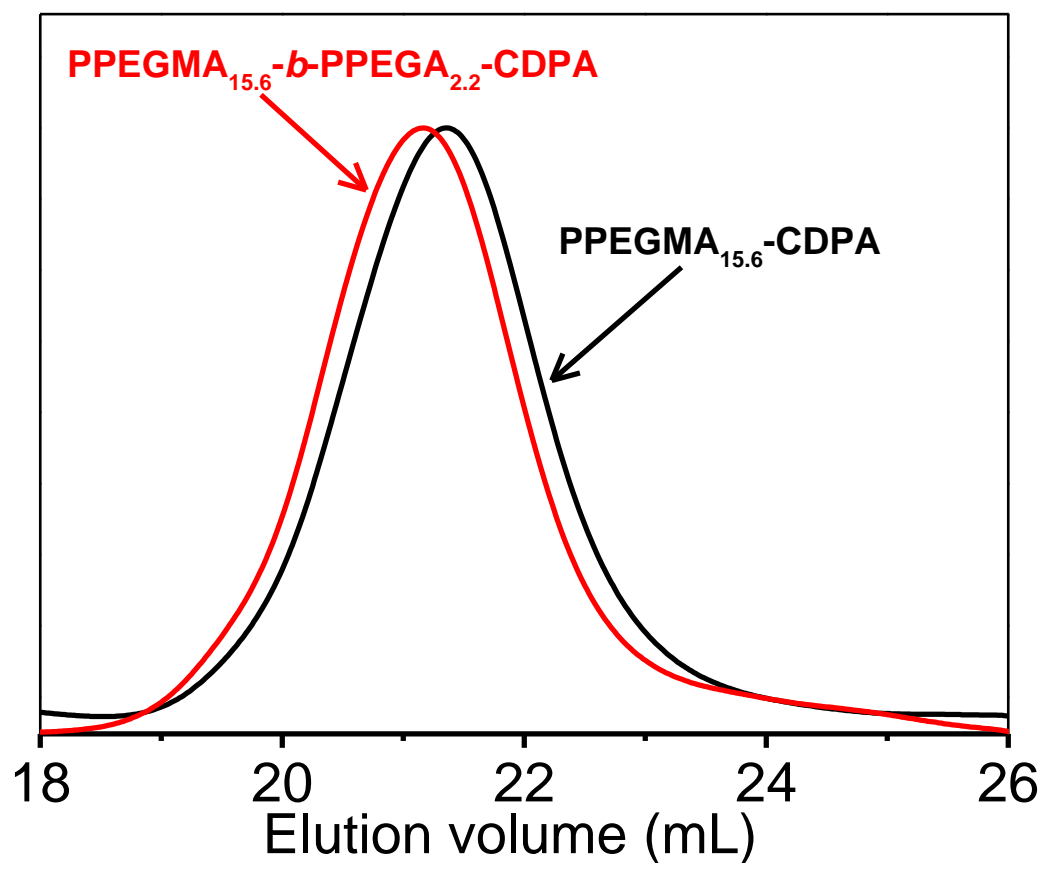

Figure S5. GPC traces of PPEGMA ${ }_{15.6}-\mathrm{CDPA}$ and PPEGMA $15.6-b-\mathrm{PPEGA}_{2.2}-\mathrm{CDPA}$.
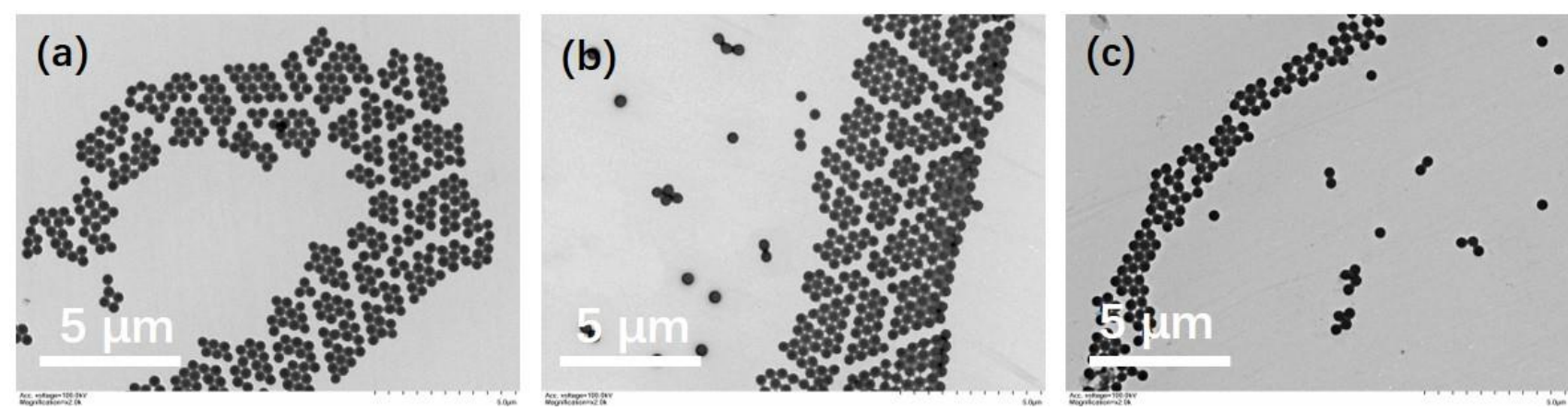

Figure S6. TEM images of PPEGMA $_{7}-b-$ PPEGA $_{1.3}-\mathrm{PHPMA}_{n}$ prepared by photoinitiated RAFT-mediated PISA of HPMA $(10 \% \quad \mathrm{w} / \mathrm{w})$ using PPEGMA $_{7}-b-\mathrm{PPEGA}_{1.3}-\mathrm{CDPA}$ as the macro-RAFT agent: (a) $n=200$, (b) $n=300$, (c) $n=400$.
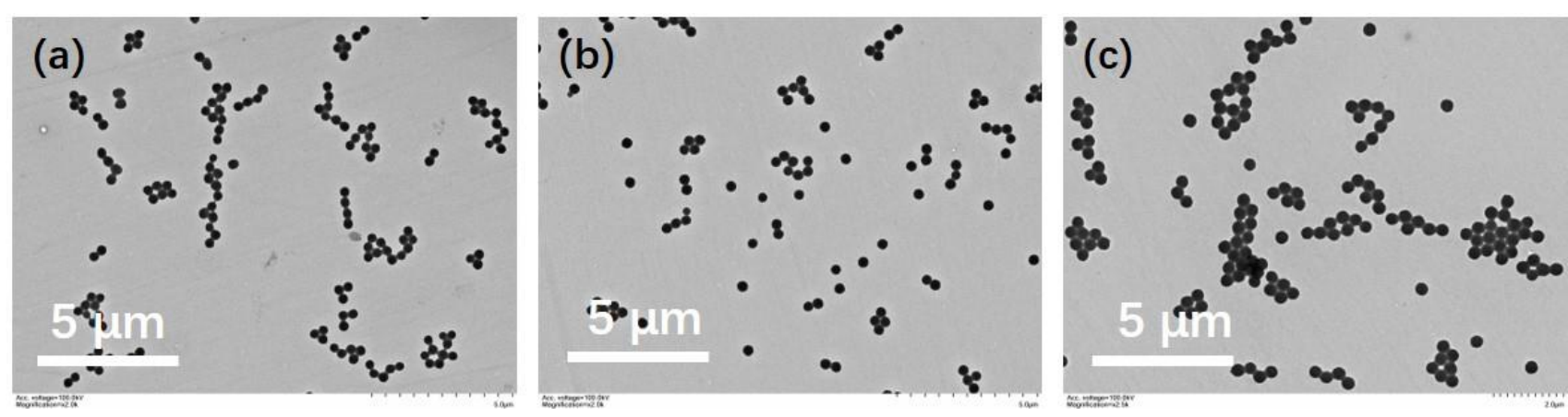

Figure S7. TEM images of PPEGMA ${ }_{15.6}-b$-PPEGA $2.2-P_{H P M A}$ prepared by photoinitiated RAFT-mediated PISA of HPMA $(10 \% \mathrm{w} / \mathrm{w})$ using PPEGMA $15.6-b-$ PPEGA $_{2.2}-\mathrm{CDPA}$ as the macro-RAFT agent: (a) $n=200$, (b) $n=300$, (c) $n=400$. 


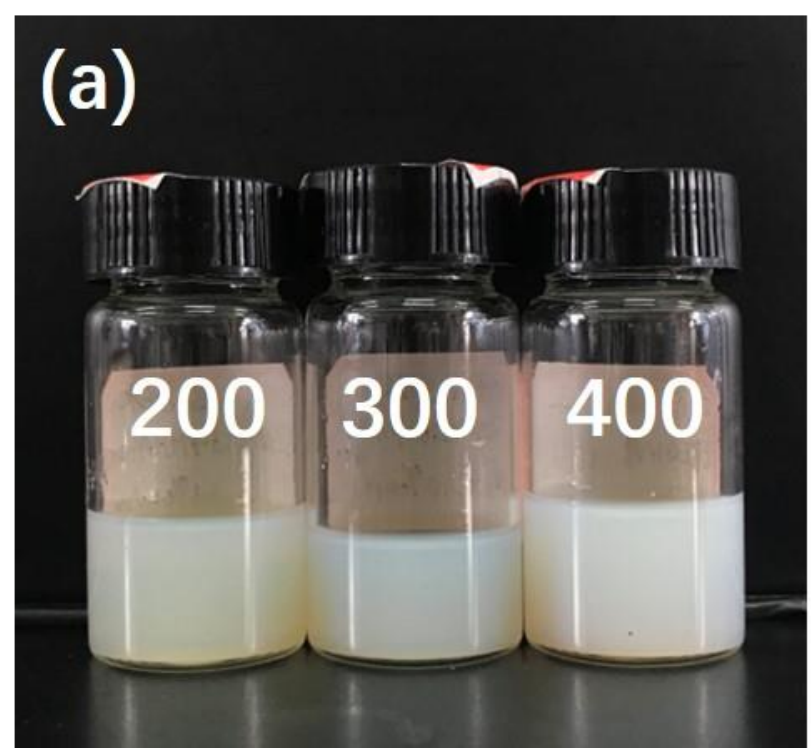

Figure S8. Visual appearance of dispersions of (a) PPEGMA $15.6-$ PHPMA $_{n}$ (b)PPEGMA 15.6 - $b$-PPEGA $2.2-$ PHPMA $_{n}(\mathrm{n}=200,300,400)$ prepared by aqueous photoinitiated RAFT-mediated PISA of HPMA, demonstrating the change in particle size.
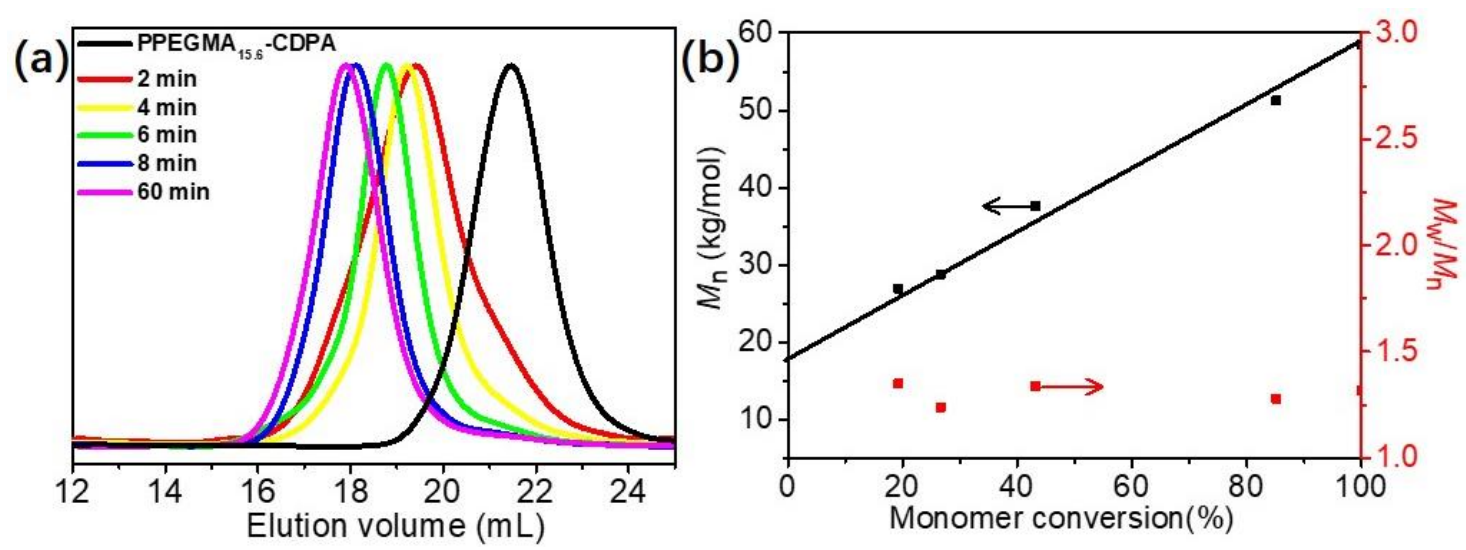

Figure S9. (a) GPC traces of PPEGMA ${ }_{15.6}$-CDPA and PPEGMA $15.6-\mathrm{PHPMA}_{n}$ withdrawn during the kinetic study of aqueous photoinitiated RAFT-mediated PISA of HPMA (20\% w/w). (b) Evolution of $M_{\mathrm{n}}$ and $M_{\mathrm{w}} / M_{\mathrm{n}}$ of PPEGMA 15.6 PHPMA $_{\mathrm{n}}$ with monomer conversion for aqueous photoinitiated RAFT-mediated PISA of HPMA $(20 \% \mathrm{w} / \mathrm{w})$.
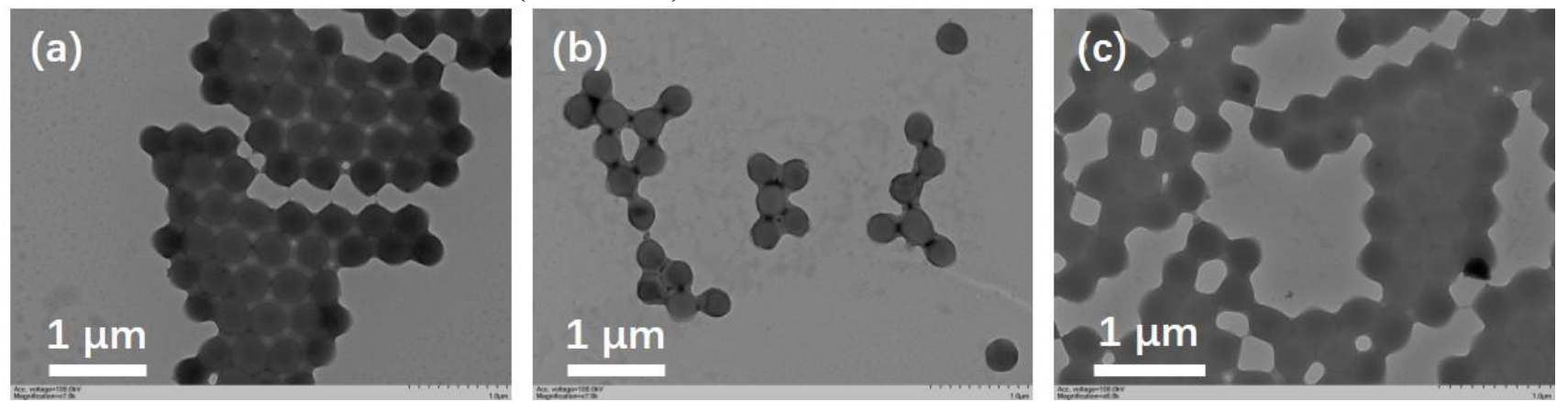

Figure S10. TEM images of PHEA $59.5-\mathrm{PHPMA}_{n}$ prepared by photoinitiated RAFT-mediated PISA of HPMA (10\% w/w) using PHEA 59.5 -CDPA as the macro-RAFT agent: (a) $n=200$, (b) $n=300$, (c) $\mathrm{n}=400$. 


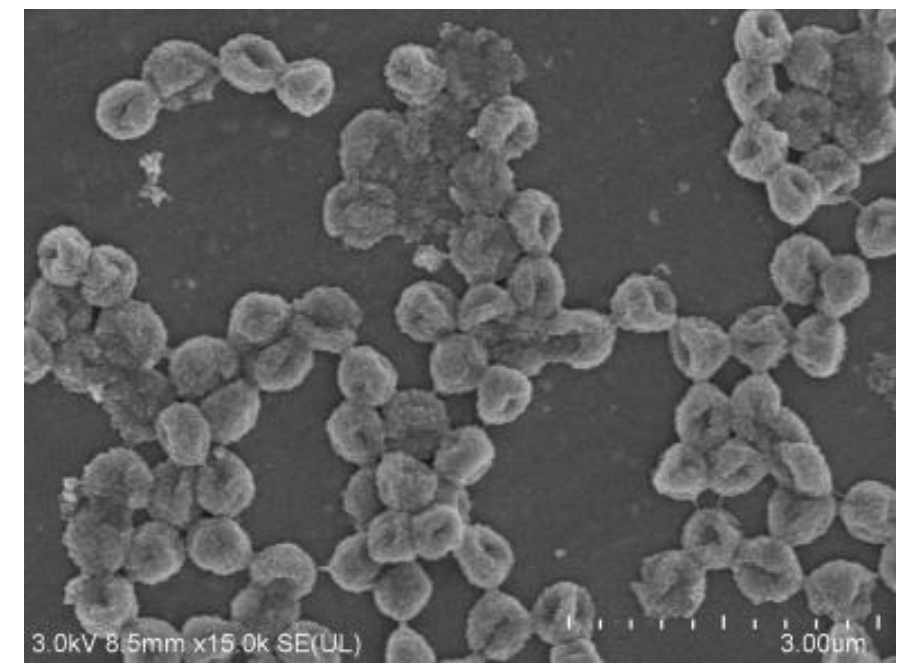

Figure S11. SEM image of cross-linked PPEGA $15.6-\mathrm{PHPMA}_{400}-\mathrm{PGlyMA}_{200} \mathrm{MBCPs}$ after dispersing in DMF.
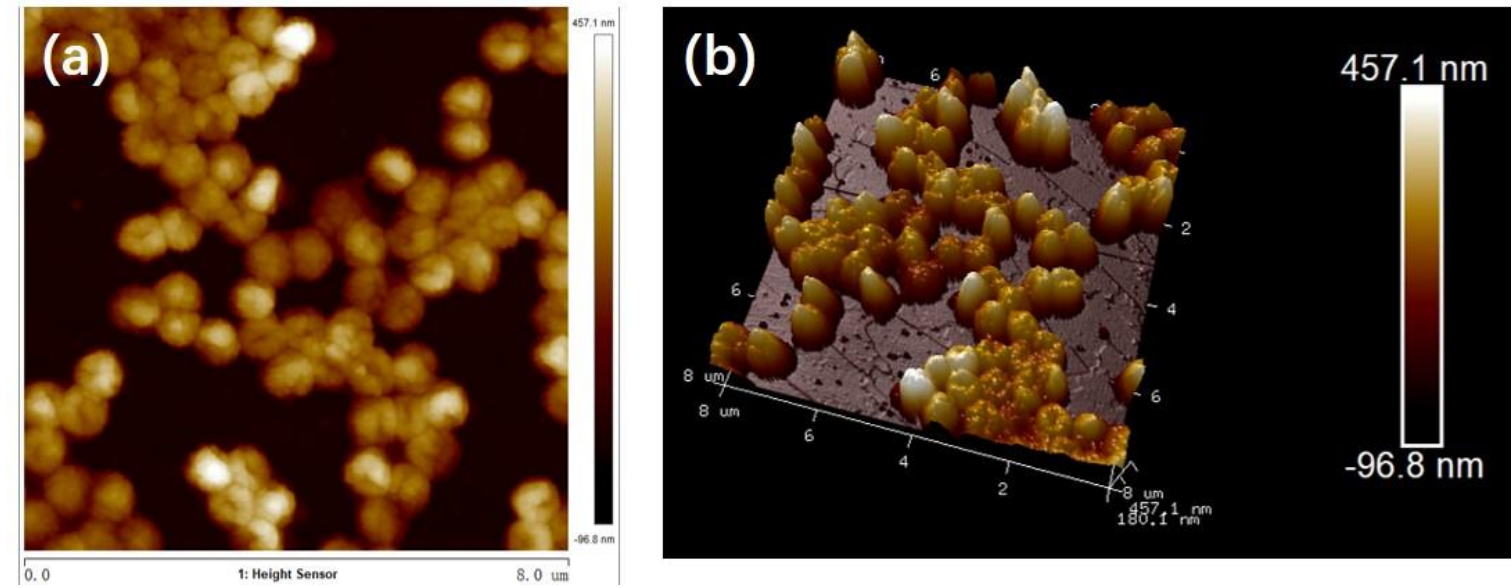

Figure S12. AFM image of cross-linked PPEGA ${ }_{15.6}-\mathrm{PHPMA}_{400}-\mathrm{PGlyMA}_{200} \mathrm{MBCPs}$ after dispersing in DMF.

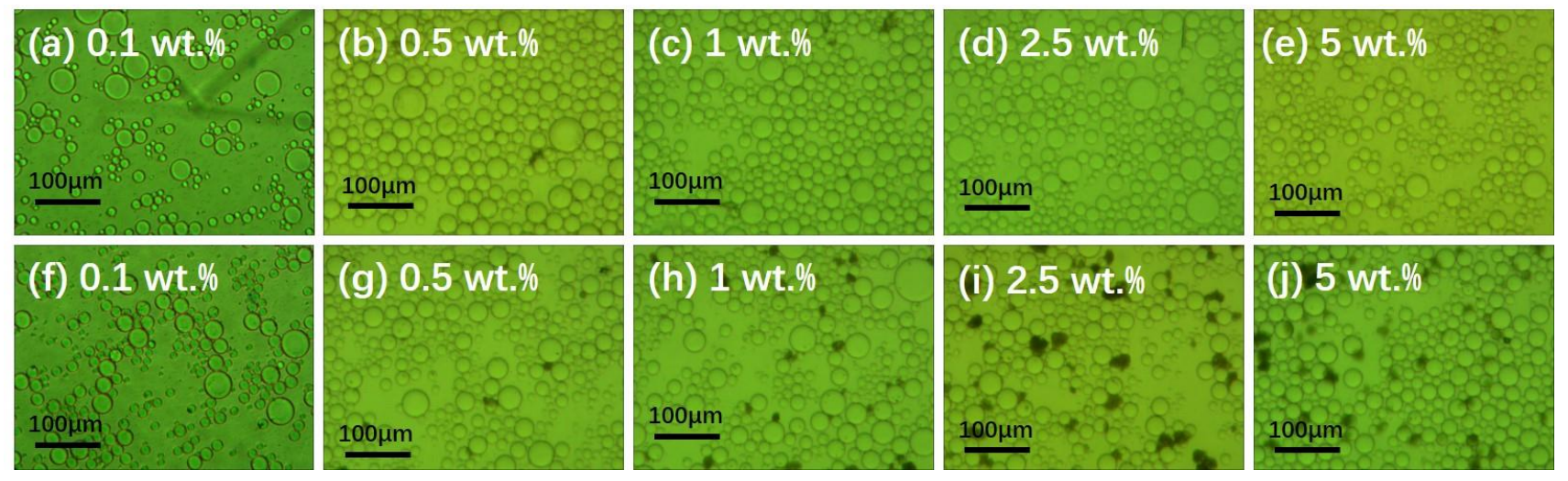

Figure S13. Optical images of hexane-in-water emulsions stabilized with different concentrations of (a-e) PPEGA 15.6 -PHPMA $400-$ PGlyMA $_{100}$ MBCPs and (f-j) PPEGA 15.6 -PHPMA $400-$ PGlyMA $_{200}$ MBCPs. 
Table S1. Hydrodynamic diameter and polydispersities obtained from DLS data for polymer particles prepared by photoinitiated RAFT-mediated PISA of HPMA.

\begin{tabular}{|c|c|c|c|c|c|}
\hline Entry number & $\begin{array}{l}\text { HPMA } \\
\text { concentration } \\
(\% \mathrm{w} / \mathrm{w})\end{array}$ & Macro-RAFT agent & $\begin{array}{l}\text { Target DP of } \\
\text { PHPMA }\end{array}$ & Diameter (nm) & Polydispersity \\
\hline 1 & 10 & PPEGMA $_{7}-$ CDPA & 200 & 362.0 & 0.163 \\
\hline 2 & 10 & PPEGMA $_{7}-$ CDPA & 300 & 458.9 & 0.080 \\
\hline 3 & 10 & $\mathrm{PPEGMA}_{7}-\mathrm{CDPA}$ & 400 & 584.8 & 0.036 \\
\hline 4 & 10 & PPEGMA $_{15.6}-$ CDPA & 200 & 47.6 & 0.236 \\
\hline 5 & 10 & PPEGMA $_{15.6}-$ CDPA & 300 & 63.7 & 0.155 \\
\hline 6 & 10 & PPEGMA $_{15.6}-$ CDPA & 400 & 74.1 & 0.061 \\
\hline 7 & 10 & PPEGA $_{7.3}-\mathrm{CDPA}$ & 200 & 320.0 & 0.094 \\
\hline 8 & 10 & PPEGA $_{7.3}-$ CDPA & 300 & 394.7 & 0.014 \\
\hline 9 & 10 & PPEGA $_{7.3}-$ CDPA & 400 & 401.7 & 0.030 \\
\hline 10 & 10 & PPEGA $_{15.6}-$ CDPA & 200 & 468.9 & 0.039 \\
\hline 11 & 10 & PPEGA $_{15.6}-$ CDPA & 300 & 502.6 & 0.005 \\
\hline 12 & 10 & PPEGA $_{15.6}-$ CDPA & 400 & 488.9 & 0.005 \\
\hline 13 & 10 & PPEGA $_{31.5}-$ CDPA & 200 & 592.6 & 0.062 \\
\hline 14 & 10 & PPEGA $_{31.5}-$ CDPA & 300 & 525.4 & 0.067 \\
\hline 15 & 10 & PPEGA $_{31.5}-$ CDPA & 400 & 553.3 & 0.095 \\
\hline 16 & 10 & $\begin{array}{l}\text { PPEGMA }_{7}-b- \\
\text { PPEGA }_{1.3}-\text { CDPA }\end{array}$ & 200 & 476.6 & 0.005 \\
\hline 17 & 10 & $\begin{array}{l}\text { PPEGMA }_{7}-b- \\
\text { PPEGA }_{1.3}-\text { CDPA }\end{array}$ & 300 & 439.1 & 0.058 \\
\hline 18 & 10 & $\begin{array}{l}\text { PPEGMA }_{7}-b- \\
\text { PPEGA }_{1.3}-\text { CDPA }\end{array}$ & 400 & 463.5 & 0.005 \\
\hline 19 & 10 & $\begin{array}{l}\text { PPEGMA }_{15.6}-b- \\
\text { PPEGA }_{2.2}-\text { CDPA }\end{array}$ & 200 & 412.4 & 0.048 \\
\hline 20 & 10 & $\begin{array}{l}\text { PPEGMA }_{15.6}-b- \\
\text { PPEGA }_{2.2}-\text { CDPA }\end{array}$ & 300 & 404.9 & 0.005 \\
\hline 21 & 10 & $\begin{array}{l}\text { PPEGMA }_{15.6}-b- \\
\text { PPEGA }_{2.2}-\text { CDPA }\end{array}$ & 400 & 425.9 & 0.012 \\
\hline
\end{tabular}




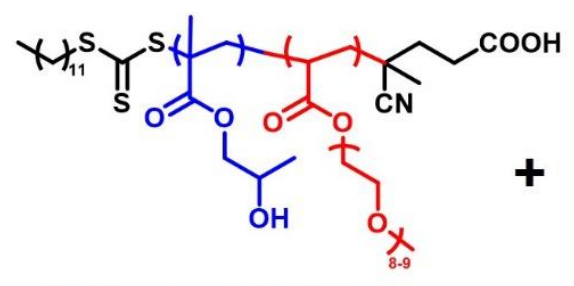

PPEGA $_{15.6}-$ PHPMA $_{400}$

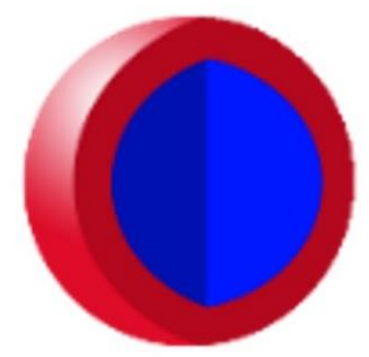

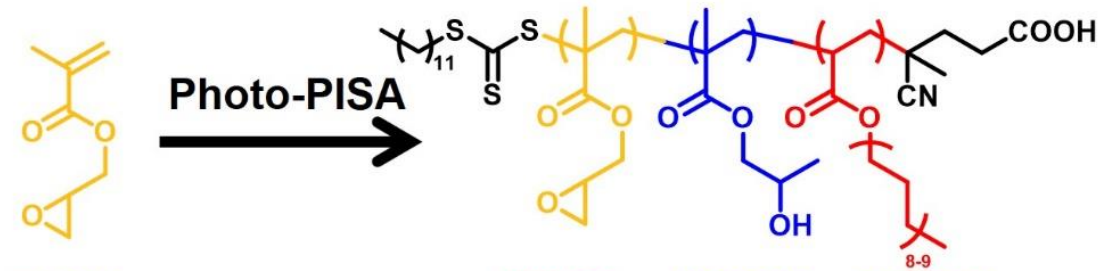

PPEGA $_{15.6}$-PHPMA ${ }_{400}-$ PGlyMA $_{n}$

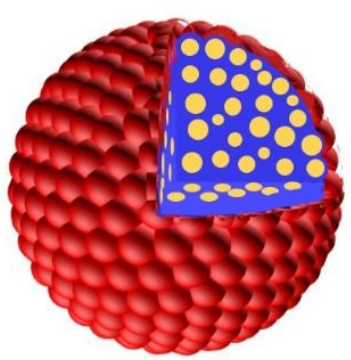

Scheme S1. Epoxy-functionalized multicompartment block copolymer particles (MBCPs) prepared by two-step photoinitiated RAFT-mediated PISA of GlyMA.

\section{REFERENCE}

1 G. Moad, Y. K. Chong, A. Postma, E. Rizzardo and S. H. Thang, Polymer, 2005, 46, 8458-8468.

2 G. Li, N. Xu, Q. Yu, X. Lu, H. Chen and Y. Cai, Macromol. Rapid Commun., 2014, 35, 14301435. 